\title{
Discrepancy among Behavioral Risk Factor Surveillance System, Social Security, and functional disability measurement
}

\author{
By Jean P. Hall, PhD, Noelle K. Kurth, MS, and Emily C. Fall, MA
}

Division of Adult Studies, University of Kansas

\section{Acknowledgements}

The research was funded by the Kansas Health Policy Authority (\#KHPA2007-055) through a grant from the U.S. Department of Health \& Human Services, Centers for Medicare \& Medicaid Services.

This brief was published in 2012 by Disability and Health Journal, Volume 5, pages 60-63. doi: 10.1016/j.dhjo.2011.08.004 
Introduction

The Affordable Care Act (ACA) of 2010 (P.L. 111-148) Section 4302 requires the development of federal standards for the measurement of disability status in order to monitor health disparities and quality of care among this population. These new data will contribute to policy, research, and funding decisions. Therefore, the validity and reliability of disability measurement instruments are important to all those who will use these data.

Of particular concern is the construct validity for measures of disability. Several authors $(1,2,3,4)$ have noted discrepancies in prevalence estimates that can occur when different survey methodologies or different measures of disability are used. A variety of federal agencies currently report differing disability prevalence rates. For example, the Census Bureau, through its American Community Survey (ACS), reports 15\% of American adults 18 years and older have disabilities (5), while the Centers for Disease Control and Prevention (CDC), through the Behavioral Risk Factor Surveillance System (BRFSS), place disability prevalence for adults 18 and older at $20 \%(6)$.

Public health officials typically use BRFSS data to identify emerging health problems, establish and track health objectives, develop and evaluate public health policies and programs, and examine health disparities among people with disabilities $(1,7,8)$. All US states and territories collect BRFSS data, making it the largest telephone health survey in the world (9). Despite the wide usage of BRFSS disability questions, the Social Security Administration (SSA) definition of disability sets the standard for accessing federal disability benefits. The SSA definition is stricter, including only those individuals with severe disabilities (10). Because the BRFSS asks respondents if they are limited in any activity while the SSA looks only at work limitations, one might expect the BRFSS to capture more people, including those with SSAdetermined disabilities. Indeed, the prevalence of people ages 18 to 64 receiving SSA disability benefits is only about $6 \%$, a population reasonably expected to be included within the larger BRFSS figure (9).

We examine here the construct validity of BRFSS disability items using a sample of adults who met the more stringent SSA definition of disability. We compare responses of this sample to the BRFSS questions to responses to a seven-part functional question. Finally, we discuss our findings, which suggest limitations in using the BRFSS for measuring disability prevalence, and implications for the new federal standards for the measurement of disability status.

\section{Methods and Materials}

This study posed the two BRFSS disability questions as part of a 69-item survey mailed in June 2009 to participants in the Kansas Medicaid Buy-In program in order to investigate the sensitivity of the questions among those with SSA-determined disabilities. The survey was sent to 1,049 people with a $38 \%$ return rate; 31 individuals did not answer the BRFSS questions, resulting in a study sample of 368 . 
Nationally, participants in Medicaid Buy-Ins must meet the SSA definition of disability and have earned income. In Kansas, they must also be between the ages of 16 and 64 (although no survey respondents were younger than 18), and be competitively employed. Demographic characteristics of the study sample were comparable to those of people ages 18 to 64 identified by the 2009 Kansas BRFSS as having a disability (5). ${ }^{1}$ The sample was $57 \%$ female, had a mean age of 49 years, and was predominantly white (88\%), with $3 \%$ reporting Hispanic ethnicity. Further, only $14 \%$ of the sample had completed 4 or more years of post-secondary education. Participants self-reported their primary disability(ies) as: mental illness (38\%), chronic illness (17\%), physical disability (23\%), intellectual disability (12\%), sensory disability (4\%), learning disability/attention deficit hyperactivity disorder (3\%), traumatic brain injury (2\%), and HIV/AIDS (1\%).

The BRFSS disability questions are "Are you limited in any way in any activities because of a physical, mental, or emotional problem?" and "Do you now have any health problem that requires you to use special equipment, such as a cane, a wheelchair, a special bed, or a special telephone?"; a yes to either question results in a person being counted as having a disability. These items were administered via a mailed survey with the sample group, whereas the BRFSS survey is administered by telephone. In the 2009 BRFSS, 26\% of Kansans aged 18-64 answered yes to one or both of the disability questions (6).

In addition to the BRFSS questions, respondents answered a seven-part functional question - "Do you have difficulty with any of the following because of an impairment or health problem?: thinking, remembering or controlling emotions; seeing, hearing or communicating; your nerves, muscles or joints; going to school and/or work; performing personal care activities (such as bathing, dressing, grooming, using the toilet or getting in and out of bed); performing household activities (such as shopping, cooking, paying bills or cleaning); moving around (including walking, using stairs, lifting or carrying objects). This question was included in the 2006 and 2008 Kansas BRFSS state-added module, but asked only of those who responded yes to one or both of the BRFSS disability questions. The question was developed using the World Health Organization (WHO) International Classification of Functioning, Disability and Health (ICF) model as a reference (11). The ICF shifts the focus of disability from cause to impact with an emphasis on function rather than pathology, i.e., having difficulty with tasks versus having innate physical, mental, or emotional "problems".

False negative responses on the BRFSS required responding "no" to both BRFSS disability questions. Similarly, a false negative response on the functional question required a response of "no" to all seven functional items. We examined the rates of false negative responses by disability type using binomial proportions, and calculated $95 \%$ confidence intervals for each proportion (Table 1). Additionally, we conducted a chi-square test to identify differences among disability types in rates of false negative responses on the BRFSS disability

\footnotetext{
${ }^{1}$ We found similar false negative rates in our 2010 survey but are waiting for the release of Kansas 2010 BRFSS data for comparison.
} 
questions. Finally, to determine the relative accuracy of the two disability survey instruments, we compared the overall false negative rate for the BRFSS to the false negative rate for the functional question using a z-test for differences in proportions

\section{Results}

Within our sample of working-age adults with SSA-determined disabilities, the BRFSS disability questions had a sensitivity of $80.7 \% ; 19.3 \%$ would not have been included in the state's BRFSS disability prevalence estimate. People within all disability-type categories screened less than $100 \%$ on the two BRFSS questions (Table 1). A chi-square test demonstrated significant differences in negative response rates by disability type $\left(\chi^{2}=24.227, d f=7, p<\right.$ .001). People with physical disabilities and those with traumatic brain injury were much less likely to be reported as false negatives than were other groups, such as those with mental illness, chronic illness or intellectual disabilities. Among those with false negative responses to the two BRFSS questions, almost two-thirds (64.8\%) answered affirmatively to having one or more functional difficulties (Table 1). Among the entire sample, the false negative rate for the functional question was $13.9 \%$, which was significantly less than for the BRFSS questions $(19.3 \%)$; the false negative rates for people with mental illness, chronic illness, or intellectual disabilities were also substantially lower on the functional question. Indeed, the functional question captured at least half of the BRFSS false negative responders in all disability categories except LD/ADHD, for whom functional difficulties may be concentrated in such areas as reading or paying attention - functions not covered by the question used in this study.

\section{Discussion}

The BRFSS questions are intended to identify and track health and risk behaviors. Survey instruments ideally use methods that are quick, low-cost, and repeatable, yet they must balance efficiency with accuracy to serve their purpose. We expect that such instruments as the BRFSS should meet empirical psychometric qualities of reliability and validity.

The SSA definition of disability is quite restricted in its focus on substantial work limitation and is recognized as applying to people with severe disabilities. Conversely, the BRFSS disability questions are sometimes considered too broad because they include people with temporary conditions and those limited in any way (12). Nevertheless, our findings suggest problems with using the BRFSS for measuring disability prevalence. In our sample of individuals with SSA disabilities, almost one in five screened as false negatives; people with self-reported mental illnesses (e.g., schizophrenia, bipolar disorder, depression), chronic illnesses (e.g., end stage renal disease, lupus, epilepsy, cystic fibrosis), intellectual disabilities, sensory disabilities, learning disabilities, and HIV/AIDS had the highest rates of false negatives.

While the cell sizes are much too small for generalizability, it is interesting to note that the "no" responders within the sensory disability category were people who are deaf or hearing impaired. While service providers and policy makers may consider these individuals to have a disability, many in the deaf community do not self-identify as such (13). In spite of this fact, 
$100 \%$ of individuals with sensory disabilities responded "yes" to the functional question regarding difficulties with seeing, hearing and communicating, indicating that, for this population especially, the functional question is more valid. Further, all of the disability groups with high levels of false negative responses to the BRFSS questions may be less likely to use special equipment and may not view their conditions as limiting their activities (e.g., those with mental illness or intellectual disabilities). Indeed, the important distinction is perhaps that the BRFSS questions emphasize limitations while the functional question refers to difficulty. People with these conditions may acknowledge difficulty in completing a task, but not feel limited, thus causing them to be under-represented by the BRFSS.

\section{Conclusion}

Data collected under Section 4302 of the ACA will be used to monitor health disparities and quality of care among people with disabilities. Our findings indicate that BRFSS questions would not fully identify this entire population. Currently, questions from the ACS are proposed as the minimum standard for use under Section 4302 (14). The ACS, with its focus on functional queries is a good foundation but, as our study indicates, additional questions that specifically address intellectual disabilities are needed to accurately represent the full spectrum of disability types $(15,16)$. McDermott and Turk note the problems in using functional questions, particularly in attributing causality (e.g., is diabetes the cause of the disability or a result of it?) (4). As an alternative they propose 3 multidimensional questions for identifying a person with a disability: (a) Do you use disability-related equipment...?, (b) Do you identify yourself as having a disability or have you received disability-related services?, and (c) If the answer is yes to either question, what is your disability? (4). The need to identify underlying conditions resulting in disability appears essential to a full understanding not only of prevalence, but to understanding the types of conditions captured or missed by the questions, and differential outcomes among people with disabilities.

As McDermott and Turk note, disability researchers must come together to reach consensus on meaningful measures of disability. Now that a minimum standard has been proposed (i.e., ACS questions), the next important task is to monitor whether data collected through future federal surveys accurately represent the entire disability population. Our findings suggest that some disability groups will not be identified in their entirety, particularly people with intellectual disabilities who had among the highest proportion of false negatives in our study. 
Table 1. False Negative Responses to Behavioral Risk Factor Surveillance Survey (BRFSS) Disability Questions and Functional Limitation Question by Self-reported Primary Disability Type among people age 18 to 64 in Kansas Medicaid Buy-In.

\begin{tabular}{|c|c|c|c|c|c|c|c|c|c|}
\hline & 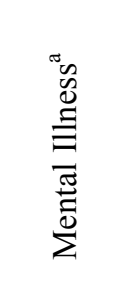 & 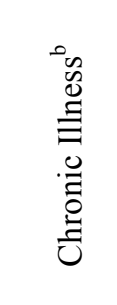 & 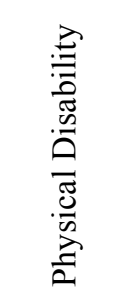 & 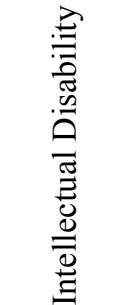 & 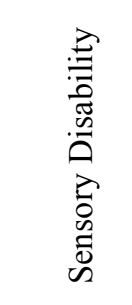 & 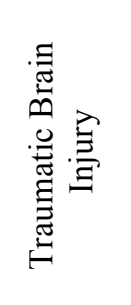 & 穿宅 & 主是 & 吾 \\
\hline Total respondents & 139 & 64 & 83 & 44 & 14 & 9 & 12 & 3 & 368 \\
\hline $\begin{array}{l}\text { False negative responses to BRFSS disability } \\
\text { questions }{ }^{\mathrm{d}}\end{array}$ & 27 & 13 & 5 & 15 & 3 & 1 & 5 & 2 & 71 \\
\hline $\begin{array}{l}\text { Percent of false negative responses within } \\
\text { disability type }\end{array}$ & $19.4 \%$ & $20.3 \%$ & $6.0 \%$ & $34.1 \%$ & $21.4 \%$ & $11.1 \%$ & $41.7 \%$ & $66.7 \%$ & $19.3 \%^{\mathrm{s}}$ \\
\hline $95 \%$ Confidence Intervals ${ }^{\mathrm{f}}$ & $\begin{array}{r}.128- \\
.260\end{array}$ & $\begin{array}{r}.105- \\
.302 \\
\end{array}$ & $\begin{array}{r}.009- \\
.111\end{array}$ & $\begin{array}{r}.201- \\
.481\end{array}$ & $\begin{array}{r}-.001- \\
.429 \\
\end{array}$ & $\begin{array}{r}-.094- \\
.316 \\
\end{array}$ & $\begin{array}{r}.138- \\
.696\end{array}$ & $\begin{array}{l}.133- \\
1.200\end{array}$ & $.152-.233$ \\
\hline $\begin{array}{l}\text { False negative responses to functional } \\
\text { question }\end{array}$ & 19 & 10 & 7 & 9 & 0 & 0 & 5 & 1 & 51 \\
\hline $\begin{array}{l}\text { Percent of false negative responses within } \\
\text { disability type }\end{array}$ & $13.7 \%$ & $15.6 \%$ & $8.4 \%$ & $20.5 \%$ & -- & -- & $41.7 \%$ & $33.3 \%$ & $13.9 \% \%^{\mathrm{g}, \mathrm{h}}$ \\
\hline $95 \%$ Confidence Intervals $^{\mathrm{f}}$ & $\begin{array}{r}.080- \\
.194\end{array}$ & $\begin{array}{r}.067- \\
.245\end{array}$ & $\begin{array}{r}.025- \\
.144\end{array}$ & $\begin{array}{r}.086- \\
.324\end{array}$ & -- & -- & $\begin{array}{r}.138- \\
.696\end{array}$ & $\begin{array}{r}-.200- \\
.867\end{array}$ & $.103-.173$ \\
\hline $\begin{array}{l}\text { False negative responders to BRFSS } \\
\text { responding affirmatively to the functional } \\
\text { question }\end{array}$ & 17 & 9 & 4 & 10 & 3 & 1 & 1 & 1 & 46 \\
\hline $\begin{array}{l}\text { Percent of BRFSS false negative responders } \\
\text { responding affirmatively to the functional } \\
\text { question }\end{array}$ & $63.0 \%$ & $64.3 \%$ & $80.0 \%$ & $66.7 \%$ & $100.0 \%$ & $100.0 \%$ & $20.0 \%$ & $50.0 \%$ & $64.8 \%$ \\
\hline $95 \%$ Confidence Intervals $^{\mathrm{f}}$ & $\begin{array}{r}.447- \\
.812\end{array}$ & $\begin{array}{r}.441- \\
.943\end{array}$ & $\begin{array}{l}.449- \\
1.151\end{array}$ & $\begin{array}{r}.428- \\
.905\end{array}$ & -- & -- & $\begin{array}{r}-.151- \\
.551\end{array}$ & $\begin{array}{r}-.193- \\
1.193\end{array}$ & $.537-.759$ \\
\hline
\end{tabular}

Notes: ${ }^{\mathrm{a}}$ Mental Illness category includes such conditions as schizophrenia, bipolar disorder, and depression. ${ }^{\mathrm{b}}$ Chronic Illness category includes such conditions as end stage renal disease, lupus, epilepsy, and cystic fibrosis. ${ }^{\circ} \mathrm{LD} / \mathrm{ADHD}$ represents learning disability and attention deficit hyperactivity disorder. ${ }^{\mathrm{d}} \mathrm{False}$ negative responses answered "no" to both of the BRFSS disability questions. ${ }^{\mathrm{e}}$ Significant differences by disability type, $\chi^{2}=24.227, d f=7, p<.001 .{ }^{\mathrm{f}}$ Confidence interval 


\section{References}

[1] Gross S, Armour BS, Courtney-Long EA, Campbell V. Disability statistics for t] states: The American Community Survey and the Behavioral Risk Factor Surveillance Syst Abstract 206194. APHA. 2009. Available athttp://apha.confex.com/apha/137am/webprogram/Paper206194.html. Accessed August 4,

[2] Kinne S, Topolski TD. Inclusion of people with disabilities in telephone health surveillance surveys. Am J Public Health. 2005;95(3):512-517.

[3] Andresen E, Fitch C, McLendon P, Meyers A. Reliablity and validity of disabili questions for US Census 2000. Am J Public Health. 2000;90(8):1297-1299.

[4] McDermott S, Turk M. The myth and reality of disablity prevalence: measuring disability for research and service. Disability and Health Journal. 2011;4:1-5.

[5] U.S. Census Bureau. 2009 American Community Survey - 1 year estimates. Ava at: http://factfinder.census.gov/servlet/ADPTable?_bm=y\&qr_name=ACS_2009_1YR_G00_DP2\&-geo_id=01000US\&ds_name=ACS_2009_1YR_G00_\&-_lang=en. Accessed July 7, 2011.

[6] Centers for Disease Control and Prevention (CDC). Behavioral Risk Factor Surveillance System Survey Data. Atlanta, Georgia: U.S. Department of Health and Human Services, Centers for Disease Control and Prevention, 2010. 2010. Available at: http://www.cdc.gov/BRFSS/technical_infodata/surveydata/2009.htm\#data. Accessed Nove 22, 2010.

[7] Armour B, Campbell V, Crews J, Malarcher A, Maurice E, Richard R. State-lev prevalence of cigarette smoking and treatment advice, by disability status, United States, 2( Prev Chronic Dis 2007;4(4):1-11. Available at:

http://www.cdc.gov/pcd/issues/2007/oct/06_0179.htm. Accessed January 12, 2011.

[8] Armour B, Swanson M, Waldman HB, Perlman S. A profile of state-level differ in the oral health of people with and without disabilities, in the U.S., in 2004. Public Healtl Reports 2008;123:67-75.

[9] National Center for Chronic Disease Prevention and Health Promotion. Behavio Risk Factor Surveillance System: About the BRFSS. 2009. Available at: http://www.cdc.gov/brfss/about.htm. Accessed November 22, 2010.

[10] Social Security Administration. Disability planner: What we mean by disabilit] Available at http://www.ssa.gov/dibplan/dqualify4.htm. Accessed July 28, 2009.

[11] Fox M, Rowland, J, Froelich-Grobe K, Vernberg D, White G, Haskett L. Determining paralysis prevalence in the United States. Disability and Health Journal. 2008; 1:172-179.

[12] Erickson W, Dumoulin-Smith A. A guide to disability statistics from the Behav Risk Factors Surveillance System. Ithaca, NY: Rehabilitation Research and Training Center Disability Demographics and Statistics at Cornell University.

[13] Lane H. Constructions of deafness. Disability \& Society. 1995;10(2):171-189. 
[14] U.S. Department of Health and Human Services, Office of Minority Health. Improving data collection to reduce health disparities. Available at:

http://www.minorityhealth.hhs.gov/templates/content.aspx?lvl=2\&lvlid=208\&id=9005 Accessed August 17, 2011.

[15] U.S. Census Bureau. The American Community Survey, Population: Question on Disability Available at http://www.census.gov/acs/www/Downloads/QbyQfact/disability.pdf. Accessed November 22, 2010.

[16] Miller K, DeMaio T. Report of cognitive research on proposed American Community Survey disability questions (Survey series: Survey Methodology \#2006-6). Washington, DC: National Center for Health Statistics, Statistical Research Division. 